\title{
CENTRALIDADE DO ENSINO MÉDIO NO CONTEXTO DA NOVA “ORDEM E PROGRESSO”
}

APRESENTAÇÃO

A publicação de um dossiê temático sobre o Ensino Médio nasce no seio dos debates e da luta contra a Medida Provisória (MP) no 746/2016, a partir da iniciativa de professores que pesquisam as políticas de educação básica e superior no Brasil, e que reconhecem que o momento exige a sistematização e socialização de estudos que possam consolidar análises históricas, sociológicas e, especificamente, das políticas educacionais que permitam aprofundar os conhecimentos sobre a radicalidade do ideário neoliberal que tomou de sobressalto o Estado e a sociedade brasileira. A organização deste dossiê também faz parte dos estudos e parcerias acadêmicas travadas durante o percurso de desenvolvimento da pesquisa "Programa Ensino Médio inovador: condiçóes de trabalho e formação docente", que contou com o apoio financeiro do Conselho Nacional de Desenvolvimento Científico e Tecnológico (CNPq).

A análise sobre o sistema educacional brasileiro geralmente leva a compreender que o Ensino Médio é a etapa da educação básica que mais provoca debates controvertidos. A rigor, seus problemas são relacionados à sua qualidade, às questóes do acesso e da permanência, à discussão sobre a sua identidade e finalidades. Na realidade, a discussão sobre Ensino Médio pode ser traduzida pela disputa por um projeto societário. Grosso modo, os liberais-conservadores insistem em aplicar os princípios que lembram a Teoria do Capital Humano. Em contraposição, segmentos da sociedade acadêmica e educacional propóem um projeto que garanta uma formaçáo ampla e integrada na perspectiva da emancipação política e social dos jovens. Ou seja, uma educação republicana que promova o ser humano acima de qualquer interesse mercantil.

Tais projetos continuam em disputa tanto no Brasil quanto nos países desenvolvidos da Organização para a Cooperaçáo e Desenvolvimento Econômico (OCDE). Em todos eles, há uma investida neoliberal que busca manter o poder político e a riqueza econômica de forma cada vez mais concentrados nas tradicionais elites. As reformas que vêm sendo empreendidas em vários segmentos da sociedade globalizada, na qual o binômio economia de mercado e democracia surge como imperativo, ditam os rumos da política em várias partes do mundo. Com diferenças sensíveis de um país para outro, a democracia representativa torna-se um regime político e os direitos humanos, seu alicerce, ambos marcados, todavia, pelas lógicas que comandam os interesses de mercado. No Brasil, após a década de 1990, podemos observar esse movimento às vezes materializado em práticas políticas, às vezes

DOI: 10.1590/ES0101-73302017179021 
como retórica por meio do anúncio de políticas públicas e econômicas muitas vezes antagônicas, mas que geraram alguns direitos, ainda que de implantação inconclusa.

Esse binômio economia de mercado e democracia mostra agora sua face mais perversa e sua incompatibilidade, em um país que permanece submisso ao jogo do capital financeiro e, portanto, pratica a mais tradicional das políticas de exclusão da população majoritária na conquista dos direitos sociais. Toda essa narrativa é construída sob o discurso democrático e com forte apelo moral. É nesse contexto que vimos o anúncio e a aprovação da Emenda Constitucional no 95/2016 por meio da Proposta de Emenda Constitucional (PEC) no 241/55, que reduz o investimento público nas áreas de saúde, educação e assistência social por 20 anos. É nesse mesmo contexto que assistimos ao anúncio e à transformaçấo em lei da MP no 746, que reforma toda a estrutura e a organização do Ensino Médio no país. É, ainda, nesse cenário que se anunciam as reformas trabalhista e da previdência. Se há algo para além do contexto socioeconômico-político que unifica tais reformas, podemos sintetizá-lo em um efeito comum: o da negação de direitos.

A MP no 746/2016 foi encaminhada pelo Ministério da Educação ao Congresso Nacional no dia 22 de setembro de 2016. Após quatro meses de tramitação, foi aprovada na Comissão Mista incumbida de apreciá-la; foi entáo convertida no Projeto de Lei no 34/2016, aprovado na Câmara dos Deputados e no Senado Federal, sendo, finalmente, sancionada como Lei $\mathrm{n}^{\circ}$ 13.415/2017 e passando a compor, desse modo, a Lei de Diretrizes e Bases da Educação (Lei no 9.394/1996).

Esse processo, porém, não passou sem que houvesse muita resistência. Da parte de estudantes, sobretudo secundaristas, o país assistiu a um amplo movimento de ocupação de prédios públicos. No ápice do movimento, aproximadamente 1.400 instituiçóes educacionais ficaram sob gestão estudantil. Em todas elas, as atividades e as discussóes giravam em torno da PEC no 241/55 e da MP no 746. De outra parte, a reaçáo contrária à MP se fez por meio das notas e dos manifestos de entidades acadêmicas e político-organizativas, das quais destacamos as que fazem parte do Movimento Nacional em Defesa do Ensino Médio: Associação Nacional de Pós-graduação e Pesquisa em Educaçáo (ANPEd), Centro de Estudos Educação e Sociedade (CEDES), Fórum Nacional de Diretores das Faculdades de Educação (FORUMDIR), Associação Nacional pela Formação dos Profissionais da Educaçáo (ANFOPE), Campanha Nacional pelo Direito à Educação, Ação Educativa, Associação Nacional de Política e Administração da Educação (ANPAE), Conselho Nacional das Instituições da Rede Federal de Educação Profissional Científica e Tecnológica (CONIF), Associação Nacional de Pesquisa em Financiamento da Educaçáo (FINEDUCA) e Confederação Nacional dos Trabalhadores em Educação (CNTE).

As posiçóes contrárias à reforma se deram pela não concordância com as duas grandes mudanças propostas: a organizaçâo pedagógica e curricular e as regras dos usos dos recursos públicos para a educaçáo. Assim se pronuncia o Movimento Nacional em Defesa do Ensino Médio, em relaçăo à primeira situação: 
Do ponto de vista da organizaçáo curricular, a MP no 746/2016 retoma um modelo já experimentado nos tempos da ditadura militar, trazendo de volta a divisão por opçóes formativas. A formação básica comum que atualmente é garantida nos três anos do Ensino Médio passaria a ser dada em apenas a metade desse tempo e, após isso, o(a) estudante seria dirigido(a) a um ou outro itinerário formativo (Linguagens, Matemática, Ciências da Natureza, Ciências Humanas ou formação técnico-profissional), a critério do sistema do ensino. Essa medida, além de significar uma perda de direito e um enorme prejuízo com relação à formação da juventude, fere a autonomia das escolas na decisão sobre seu projeto político pedagógico, o que hoje está assegurado na Lei de Diretrizes e Bases da Educação (LDB) e que será alterado pela Medida Provisória (MOVIMENTO NACIONAL EM DEFESA DO ENSINO MÉDIO, 2016).

Além da proposição citada, a referida MP traz como alteraçóes a retirada da obrigatoriedade das disciplinas de Educação Física, Artes, Filosofia e Sociologia e a possibilidade de que seja atribuída habilitação para docência a quem não possui a formação específica, por meio do reconhecimento de "notório saber" para atuação no itinerário formativo do Ensino Técnico e Profissional. A ampliaçâo da jornada escolar também compóe os objetivos da MP no 746 , sendo prevista a criação de um programa provisório de apoio financeiro aos estados.

A outra grande alteração diz respeito ao financiamento. Com vistas a garantir a oferta de formação técnica e profissional, passa a ser permitido o uso de recursos do Fundo de Manutenção da Educaçẫo Básica (FUNDEB) para realização de parcerias entre as redes públicas e o setor privado, anunciando uma ampla açáo de privatizaçáo da escola pública de Ensino Médio. Ao final da tramitação, a lei incorporou ainda a possibilidade de que tais parcerias sejam destinadas à oferta de estudos na modalidade à distância, que poderão ser cursados pelos estudantes e integralizados em seus currículos. Essas mudanças trazem em seu bojo a ampliação da autonomia dos gestores públicos responsáveis pela oferta do Ensino Médio, sobretudo nas redes estaduais de ensino. No contexto de crise fiscal dos estados, o poder decisório desses gestores tem grande chance de ser guiado muito mais pela lógica do que "podem" do que pelo que "devem" fazer para a garantia do direito à educação para a população das classes populares.

Seja pela razáo exposta no último parágrafo, isto é, a forma fluida e ambígua com que a lei trata a gestáo das redes escolares; seja pela fluidez conferida também à organização pedagógico-curricular; seja pela insegurança quanto à oferta, à formação de professores e ao exercício da docência; seja pela promiscuidade com relação ao financiamento da educação, o conjunto de mudanças nos levam a alcunhá-lo de "Ensino Médio líquido", haja vista que nesse quadro não há solidez possível para a formação humana.

Todas essas medidas foram alvo de polêmica e reaçáo contrária, como atestam os vários manifestos e notas; ainda assim, foram aprovadas pelo Congresso Nacional, em uma clara sinalização de que, no contexto político pelo qual passa o país, a população não 
será ouvida. E, ainda, que estava sendo reconhecida a centralidade da educação para a consolidação do projeto político parido no contexto do impeachment de Dilma Rousseff e dos grupos econômicos e políticos que lhe deram sustentaçáo.

A MP no 746/2016, além de apresentar uma forma autoritária de fazer política educacional, apresenta um conteúdo que banaliza a formação no Ensino Médio, rompendo com o prescrito na Lei de Diretrizes e Bases, que lhe havia atribuído a responsabilidade de consolidar e aprofundar os conhecimentos adquiridos no Ensino Fundamental; dar uma preparação básica para o trabalho e para a cidadania, com desenvolvimento da autonomia intelectual e do pensamento crítico. A experiência histórica nos dá a devida certeza de que essa contrareforma não alcançará uma melhoria da qualidade da última etapa da educaçáo básica. Muito pelo contrário, ela tende a aumentar a desigualdade escolar e a piorar o desempenho dos alunos.

Os pesquisadores convidados a compor a escrita deste dossiê são referências no campo da análise de políticas sociais e educacionais. Suas contribuiçōes se mostram relevantes para a crítica, de modo a revelar as experiências de políticas de Ensino Médio implantadas nos últimos decênios, sobretudo no Brasil e, em particular, no atual contexto. Como um dos argumentos em defesa da reforma é de que o Brasil precisa se ajustar às experiências internacionais, compõem também o dossiê análises sobre a realidade de outros países. A seguir, apresentamos os artigos.

Para abrir o dossiê, apresentamos o texto "A contrarreforma do Ensino Médio no contexto da nova ordem e progresso", de Eliza Bartolozzi Ferreira. A autora argumenta que a MP no 746 e a lei que nela tem origem (Lei n ${ }^{\circ} 13.415 / 2017$ ) retomam e revigoram características de três momentos das políticas educacionais no Brasil: o da ditadura Vargas, o da ditadura militar e o contexto da década de 1990. Esses períodos foram marcados pelo aprofundamento das desigualdades educacionais, o que se apresenta como potencialidade na contrarreforma atual do Ensino Médio, além de reiterar interesses privatistas. Para a autora, esse contexto se coloca em oposiçáo às "experiências vividas durante o governo democrático-popular (2003-2015) de inclusão social e de participação dos diversos segmentos da sociedade".

O segundo texto, "Estado e capitalismo no Brasil: a inflexão atual no padrão das políticas públicas do ciclo político da Nova República”, é um ensaio de Marcio Pochmann que contribui para a reflexáo rigorosa acerca do contexto econômico, político e social no qual a reforma do Ensino Médio se engendra. O texto é estruturado em duas partes: a primeira se ocupa de desenvolver uma elaboraçáo teórica acerca "da noção de determinantes na relação do Estado no capitalismo brasileiro"; a segunda analisa o momento atual, considerado de desconstrução do padrão de políticas consolidado no período da Nova República, em que se exercitou a experiência democrática. Desse modo, o autor evidencia que o contexto recente se mostra adequado à profusão do ideário neoliberal e do projeto excludente de sociedade que lhe é característico.

O artigo de Acácia Kuenzer, "Trabalho e escola: a flexibilização do Ensino Médio no contexto do regime de acumulaçáo flexível", tem como objetivo analisar a re- 
forma do Ensino Médio, regulamentada pela Lei no 13.415/2017, no âmbito do regime de acumulação flexível. A autora afirma que essa reforma se propóe a flexibilizar o Ensino Médio, pela possibilidade de escolha, pelo aluno, de um percurso de formaçáo em uma área acadêmica ou técnica e profissional, a partir de sua trajetória e de seu projeto de vida, desde que assegurada a base nacional. Após uma breve exposiçấo dos principais pontos da reforma e das críticas que ela vem sofrendo, o texto a analisa de dois pontos de vista: o ontológico e o epistemológico. Do ponto de vista ontológico, aponta que a reforma do Ensino Médio responde ao alinhamento da formação ao regime de acumulação flexível. Analisada a base material que deu origem à reforma, do ponto de vista epistemológico o texto confronta as concepçóes moderna e pós-moderna de conhecimento e aprendizagem quando trata das concepçóes de protagonismo do aluno e do professor.

Na sequência, Gaudêncio Frigotto e Vânia Cardoso da Motta discutem as razóes pelas quais se propóe urgência para a $\mathrm{MP} \mathrm{n}^{\circ}$ 746. Para isso, com base principalmente em Antonio Gramsci e Florestan Fernandes, tomam por referência os sujeitos da reforma e o quadro de regressão teórica e política que marca o atual contexto. Ao final da análise, os autores indicam que a proclamada urgência tem por fim "administrar a questão social [...], parte constitutiva das relaçóes sociais capitalistas", que culmina por negar aos jovens o acesso aos fundamentos das ciências que lhes permitiriam compreender "o mundo das coisas e a sociedade humana".

O texto de Luiz Antonio Cunha situa o Ensino Médio no contexto da reforma como um "atalho para o passado". $\mathrm{O}$ autor insere as propostas anunciadas pela MP no $746 \mathrm{em}$ um quadro analítico que permite reconhecer as aproximaçóes com a Lei $n^{\circ}$ 5.692/1971 e com o Decreto no 2.208/1997. Em qualquer uma das três situaçóes, evidencia-se um objetivo comum, qual seja, o de conter a demanda pela ampliaçáo da oferta da educação superior. Além disso, assevera o autor, "no caso da medida provisória, essa funçáo deriva, também, de uma particular crise das instituiçóes privadas de Ensino Superior, que tem levado a uma inédita centralização empresarial e concentração do capital". Ao situar esse cenário no contexto das medidas de contenção do gasto público, o autor caracteriza uma das faces mais perversas da reforma, que poderá levar à retomada de velhas propostas de transferência de universidades públicas para o setor privado.

Celso Joāo Ferreti e Monica Ribeiro da Silva, no texto "Reforma do Ensino Médio no contexto da Medida Provisória 746/2016: Estado, currículo e disputas por hegemonia", adotam o argumento central de que as políticas curriculares se instituem como espaços de disputa por hegemonia. Com base no conceito de Estado ampliado, formulado por Gramsci, os autores situam as políticas de reforma curricular do Ensino Médio formalizadas no Brasil nos últimos 20 anos. Os argumentos são desenvolvidos a partir de análises das audiências públicas do Congresso Nacional que debateram a MP no 746 e, também, do documento da Base Nacional Comum Curricular, produzido pelo Ministério da Educação.

O artigo seguinte, "O Ensino Médio e as comparaçôes internacionais", de Carmen Sylvia Vidigal Moraes, objetiva analisar a universalização e a obrigatoriedade da 
educação básica e as condições estruturais da educação considerada bem-sucedida em países como Inglaterra e Finlândia. A análise foi realizada com base em fontes primárias e secundárias, a partir do método comparativo, com o intuito de compreender os "baixos níveis de aprendizagem" no Brasil, medidos pelo Programa Internacional de Avaliação de Estudantes (PISA) de 2015.

O último texto deste dossiê, "Natureza do conhecimento e currículo poderoso no Ensino Técnico Profissional: uma análise sociológica a partir do caso de Moçambique", de Nelson Casimiro Zavale, se baseia na reforma do Ensino Técnico Profissional (ETP) de Moçambique. O artigo examina a natureza do conhecimento poderoso e os processos epistêmicos e sociais subjacentes ao currículo do ETP. Teoricamente, o artigo revisita criticamente o conceito de conhecimento poderoso enraizado no realismo social e se baseia na teoria de diferenciação curricular de Shay. O artigo conclui que, no ETP, o currículo poderoso pode resultar da combinação de várias formas de conhecimento, nomeadamente teórico, prático, profissional e genérico; o currículo do ETP resulta da recontextualização dessas formas de conhecimento, através de processos de regulação social.

Em vista do complexo cenário que se avizinha, esperamos que o material disponibilizado contribua para a compreensão dos textos e contextos que marcam a contrarreforma da última etapa da educação básica, consolidada na Lei no 13.415 , no início do ano legislativo de 2017. Esperamos, também, que contribua para o acompanhamento crítico e as intervençóes necessárias ao processo de implementação da contrarreforma, de modo a minimizar os efeitos perversos que, certamente, as mudanças traráo para as escolas públicas de Ensino Médio, seus estudantes e educadores. Boa leitura!

Eliza Bartolozzi Ferreira ${ }^{1}$ Monica Ribeiro da Silva ${ }^{2}$

\section{Referência}

MOVIMENTO NACIONAL EM DEFESA DO ENSINO MÉDIO. Manifesto do Movimento Nacional sobre a Medida Provisória: não ao esfacelamento do ensino médio. 2016. Disponível em: <http:/www.observatoriodoensinomedio.ufpr.br/wp-content/uploads/2014/05/ManifestoMovimento-sobre-a-MP-do-Ensino-M\%C3\%A9dio.pdf $>$. Acesso em: 3 mar. 2017.

\footnotetext{
${ }^{1}$ Universidade Federal do Espírito Santo - Vitória (ES), Brasil. E-mail: eliza.bartolozzi@gmail.com
}

${ }^{2}$ Universidade Federal do Paraná - Curitiba (PR), Brasil. E-mail: monicars03@gmail.com 